\title{
RASTROS DE UMA PRODUÇÃO EM BIBLIOTERAPIA E DA ATUAÇÃO DO BIBLIOTECÁRIO EM INTERVENÇÕES BIBLIOTERÁPICAS: UMA ANÁLISE A PARTIR DA BASE DE DADOS EM CIÊNCIA DA INFORMAÇÃO (BRAPCI)
}

\author{
Ana Caroline Oliveira da Silva \\ Orientanda \\ Graduada em Biblioteconomia \\ carol.mariaeduarda2@gmail.com
}

Lucas Veras de Andrad

Orientador.

Professor das Séries Inicias da Educação Básica da Secretaria Municipal de Educação de Teresina

lukkandrade18@hotmail.com

\section{Resumo}

O presente trabalho tem como tema a biblioterapia. Ela pode ser entendida como uma técnica que visa a mudança de comportamento dos sujeitos através do autoconhecimento, mediante princípios (catarse, humor, identificação, projeção, introjeção e introspecção) por meio de linguagens diversas (música, literatura, pintura, entre outras). Nesse sentido, ela é capaz de permitir ao indivíduo a compreensão dos seus conflitos, mediante o diálogo de si em interpretação com essas linguagens. Assim, ela se demonstra como uma ferramenta favorável para quem não consegue lidar com problemas diários da vida e/ou enfermidades distintas. O uso da biblioterapia não é recente, no entanto, é pouco difundida e os estudos sobre a temática ainda se mostram bem escassos. Partindo desta noção, temos o seguinte questionamento: Qual o panorama da pesquisa em biblioterapia no Brasil? Neste interim, tem-se como recorte a área de Biblioteconomia e Ciência da Informação (CI), o periódico científico e o estudo sobre a Base de Dados em Ciência da Informação (BRAPCI). Base essa, em forma de repositório, que é considerada a mais completa relacionada a produção de periódicos científicos dentro da Ciência da Informação (CI) no Brasil. Desse modo, descortina-se como objetivo geral: Rastrear a produção científica em biblioterapia, tendo por base periódicos em Biblioteconomia e (CI) a partir da (BRAPCI). Estabelecendo ainda como objetivos específicos: Refletir de forma breve a divulgação científica, desde o seu surgimento, perpassando pela divulgação em periódicos, de modo, a destacar a área de (CI) até apresentarmos a (BRAPCI), como fonte de informação para a pesquisa e pesquisadores; Apresentar a biblioterapia, de modo a demonstrar conceitos, princípios, tipologias, assim como, evidenciar o enlace entre biblioterapia, biblioteconomia e (CI). E por último, apresentar o bibliotecário na prática do universo da biblioterapia, uma vez que refletimos a partir dos textos levantados, quais atividades são desenvolvidas na prática biblioterápica, que noção de biblioterapia é admitida nos espaços em que atua esse profissional, entre outros aspectos. Nesse sentido, a pesquisa se desenvolve sob o viés bibliográfico, trabalhando na produção de dados a perspectiva quanti-qualitativa, a partir de um recorte temporal (19752017), limitando ainda os estudos a área geográfica do Brasil. Os resultados indicam a biblioterapia como ferramenta relevante para o auxílio das pessoas, de forma a trabalhar seus problemas. O panorama sobre a temática que traçamos, constatou que as pesquisas na área ainda se mostram escassas, principalmente quando retratam o empirismo das intervenções. Verifica-se o bibliotecário a frente e ativamente nos processos em bilbioterapia, o que refuta a ideia que alguns autores pontuam sobre este de atuarem apenas no planejamento com a seleção e indicação de obras nas práticas. Por fim, observa-se que a grande maioria dos trabalhos representam atividades em biblioterapia via extensão universitária, desenvolvida por estudantes sob orientação de um professor, o que favorece ao entendimento que embora seja um campo de atuação, essa prática profissional ainda não encontra-se consolidada.

Palavras-Chave: Bibliotecário. Biblioterapia. Divulgação Científica. Periódico Científico. BRAPCI. 
